\title{
REGISTRAR E CRIAR: IMPULSOS À AUTORIA DOCENTE NAS AULAS DE LITERATURA
}

\author{
RECORDING AND CREATING: IMPULSES TO \\ THE TEACHING AUTHORSHIP IN LITERATURE LESSONS
}

\section{Marguit Carmem Goldmeyer ${ }^{1}$}

Recebido em: 15 de maio de 2017

Aprovado em: 20 de junho de 2017

Sistema de Avaliação: Double Blind Review

RPR | a. 14 | v. 2 | p. 51-60 | jul./dez. 2017

\section{RESUMO}

Pelo presente trabalho pretende-se apresentar e instigar reflexões acerca de recursos metodológicos adotados em sala de aula, no ensino superior, para promover a autoria de estudantes de licenciaturas. Acredita-se que a vivência de momentos de autoria na academia e a análise desses serão um impulso para as transformações na sala de aula da educação básica.O discurso na academia, no momento, está bastante direcionado à metodologia ativa, focada na participação dos alunos e na resolução de problemas. A angústia de muitos docentes consiste no "como"? Como planejar aulas com um aprofundamento adequado do conteúdo, voltado para o desenvolvimento de competências diversas e, de preferência, com o uso da tecnologia? Mudanças na metodologia de ensino urgem. Com o intuito de ajudar nesta reflexão, compartilha-se os resultados de trabalhos realizados no ensino superior com ênfase na produção coletiva de textos postados numa página do facebook. Os diferenciais estão na observação do "fio condutor" entre as temáticas abordadas em aula, na autoria dos estudantes que escrevem partes do texto coletivo, no uso da tecnologia e na análise conjunta do texto produzido. O trabalho está sendo desenvolvido há quatro anos consecutivos e os resultados já são perceptíveis na atuação dos acadêmicos nos estágios e nas escolas em que atuam como docentes formados. O compartilhamento da pesquisa provocará perguntas e será um convite para o trabalho diferenciado. na educação básica e também no ensino superior.

Palavras-chave: Metodologia. Aulas interativas. Criação. Registro.

\begin{abstract}
The present work intends to present and instigate reflections about methodological resources adopted in the classroom, in higher education, in order to promote the authorship of undergraduate students. It is believed that the experience of moments of authorship in the academy and their analysis will be a major stimulus for the changes in the classroom of basic education. The discourse in the academy, at the moment, is aimed at active methodology, focused on the participation of the students and problem solving. The distress of many teachers is "how"? How to plan classes with adequate content deepening, focused on the development of diverse skills and, preferably, with the use of technology? Changes in teaching methodology are urgent. In order to help in this reflection, we share the results of works carried out in higher education with emphasis on the collective production of texts posted on a Facebook page. The differences are in the observation of the "guiding thread" between the topics addressed in class, the authorship of students who write parts of the collective text, the use of technology and the joint analysis of the text produced. The work is being developed throughout four consecutive years and the results are already perceptible in the performance of the academics in the internships and in the schools in which they act as trained teachers. Sharing the survey will prompt questions and will be an invitation to work differently bothin basic education and in higher education.
\end{abstract}

Keywords: Methodology. Interactive classes. Creation. Record.

\footnotetext{
${ }^{1}$ Doutora em Teologia pela Faculdade EST (São Leopoldo/Brasil). Professora no Instituto Superior de Educação Ivoti (Ivoti/Brasil). E-mail: marguit.goldmeyer@institutoivoti.com.br.
} 


\section{INTRODUÇÃO}

Na educação básica, percebe-se que a reflexão sobre como o aluno aprende e a relevância disso no jeito do professor ensinar, ocupa um lugar de destaque, nos momentos de diálogo pedagógico. Compreender como o aluno aprende para saber como ensinar melhor instiga professores a reverem a sua prática. Igualmente, muitos docentes sentem uma inquietude quando ouvem falar da necessidade da inovação e na utilização da metodologia ativa nas aulas do ensino superior. Sentem dificuldade de imaginar aulas interativas, em que os conteúdos programáticos da disciplina estejam garantidos e que a função docente consista na mediação do processo de aprendizagem e não na ação de dar aulas.

Assim surgem as perguntas: mas qual é o espaço da reflexão sobre este tema no ensino superior? Ou ainda: como ocorre, realmente, o processo de ensino e aprendizagem no ensino superior? Talvez alguns questionem a necessidade desta reflexão, por que pressupõe que seja algo óbvio, automático: professor ensina e aluno aprende. Baseiam no pensamento: "Ora, são adultos.".

Certamente, é desejo de todos os envolvidos que a aprendizagem ocorra. É necessário, todavia, rever alguns conceitos, como por exemplo, a eficácia da transmissão unidirecional de conhecimento, em que os professores dão sua aula no estilo palestra, usam o data-show como recurso, mostram muitas lâminas ricas em conteúdo, mas não instigam para a participação ativa dos alunos. A consolidação do aprender pressupõe envolvimento dos aprendentes, compartilhamento de conhecimentos prévios que serão o ponto de partida para a construção e reconstrução de saberes, cooperação entre os sujeitos, interação e a constante busca por significados.

Não basta dizer aos estudantes dos cursos de licenciatura que eles devem promover a autonomia dos alunos se, na universidade, os jovens não vivenciam a metodologia ativa e não são instigados à criação e à autonomia do pensar e do fazer. Eles, atuando nas escolas, meramente, reproduzirão modelos conhecidos na época de alunos da educação básica ou adotarão e modelos vistos na faculdade, onde a postura, geralmente, é apenas de escuta.

Moças de diferentes idades, algumas bem jovens, outras já com uma história de vida mais longa, um ou outro rapaz enchem as salas de aula dos Cursos de Licenciatura em Pedagogia de sonhos e de esperanças. Como? pergunta-se a sociedade. O que desejam de uma profissão tão desacreditada? O salário que ganham nem paga as contas do mês, afirmam algumas pessoas. No entanto, a maioria dos que optam pela docência sabem muito bem o que buscam e, justamente, para transformarem estes discursos, optam pelo ensino na Educação Infantil e nos Anos Iniciais, pois acreditam que, dando uma boa base na educação das crianças, as mudanças ocorrerão.

Motivados por estas indagações e a necessidade de oferecer suporte reflexivo aos futuros docentes, surgiu o Projeto (In)sana realizado no Curso de Licenciatura-Pedagogia com os estudantes matriculados na disciplina de Literatura Infantil. Cabe destacar que a essência do projeto é sempre a mesma, mas a cada ano, o projeto ganha um novo nome, pois os estudantes, depois de ouvirem a proposta e de trazerem suas contribuições e, muitas vezes, até de debaterem o tema, em conjunto, definem o foco do projeto e batizam-no. Por conseguinte, apresentaremos os resultados dos trabalhos realizados com a ênfase na produção coletiva de textos postados numa página do facebook. Os passos do projeto consistem em: a) docente apresenta a proposta aos estudantes; b) definir, em conjunto, o tema e escolher os protagonistas da história e o cenário; c) decidir o dia para o qual cada autor estudantil escreverá e apresentará seu texto; d) combinar detalhes para a criação da página do Facebook, assim como as regras da produção do texto semanal. Segunda fase: e) semanalmente, nos sete minutos iniciais da aula, um estudante abre a página do facebook e compartilha sua produção textual; f) grupo observa, analisa e comenta os seguintes aspectos: contemplação de forma sucinta dos conteúdos abordados na 
aula anterior, continuidade da história, observância da coesão e da coerência e se o final da história permite ao próximo autor dar continuidade à obra escrita coletiva; g) se necessário, realiza-se ajustes e correções no texto.

A produção do texto coletivo e também o momento de socialização das produções exige das estudantes a capacidade de sintetizar ideias estudadas na aula, a pesquisa para complementar conceitos ou ideias abordadas, o domínio dos conteúdos, criatividade no tecer dos pensamentos e também a abertura ao diálogo e às críticas das colegas em relação ao texto apresentado.

Observamos que o ensino da literatura que passa pela percepção dos olhos e pelas batidas do coração produz sentidos, como afirma Alves (2005, p. 81) "O início do pensamento se encontra nos olhos que têm capacidade de se assombrar com o que veem". Estudantes, que durante sua vida acadêmica, exercitam o olhar investigativo e curioso, certamente, depois, no exercício da profissão, promoverão essa vivência também aos seus alunos.

Nesse contexto, o presente artigo apresenta propostas de como tecer uma rede de relações entre a vida e a literatura, tendo como aliado o registro que leva à reflexão individual e coletiva, ao diálogo, à participação e ao protagonismo docente. A experiência da leitura e da vivência da literatura contribuirão para a atribuição de significados ao mundo, à vida e para a constituição da identidade docente. Cabe citar as palavras de Barthes proferidas em janeiro de 1977, na aula inaugural do Colégio de França, reafirmando a importância da literatura "se, por e não sei que excesso de socialismo ou e barbárie, todas as nossas disciplinas devessem ser expulsas do ensino, exceto uma, é a disciplina literária que devia ser salva, pois todas as ciências estão presentes no monumento literário" (BARTHES, 1977, p. 90).

\section{AULAS INTERATIVAS NO ENSINO SUPERIOR: VIVENCIAR PARA MEDIAR CONHECIMENTOS}

As contribuições do presente artigo direcionam-se para o ensino superior, mas a reflexão é válida e necessária para todos os níveis de ensino. Parte-se de alguns questionamentos: Como preparamos nossas aulas no ensino superior? Preparamos? Como usamos os recursos tecnológicos? Que estratégias metodológicas adotamos e por quê? Merece destaque a contribuição de Francisco Imbernón (2012, p. 9) "É preciso lembrar que o importante não são as diversas metodologias ou técnicas de ensino como um fim em si mesmo, mas a preocupação do professor ou da professora com a aprendizagem dos alunos, e como esta se origina em todo o processo de ensino."

Trabalhar de jeito diferente exige coragem de mudar, de inovar e de arriscar um pouco, porque pela participação e questionamentos dos estudantes, a aula pode mudar de direção e como professores temos que estar muito bem preparados e com "cartas na manga" para não perdermos o foco, mas permitirmos e incentivarmos uma abordagem mais transversal, que valoriza a pesquisa e a participação dos acadêmicos. Nem sempre as estratégias que escolhemos com a melhor das intenções, são exitosas, pois lidamos com pessoas e estas reagem de forma diferente diante dos desafios. Alguns participam sempre, outros se tiverem que pensar muito, não gostam. É cômodo também para o estudante ficar sentado simplesmente ouvindo, confiante em receber depois os slides apresentados para, a partir deles, estudar para a prova. Preparar a aula, pensando "Se eu fizer assim, eu provocarei tais reflexões... se eu der aquele texto, eles terão o embasamento teórico para o próximo passo que é... se eu usar esta frase, provocarei o grupo para que tragam seus conhecimentos prévios de uma maneira espontânea", ou ainda, "se a aula iniciar com um estudo de caso sobre o qual os estudantes já tiveram a tarefa de pesquisar, conseguiremos aliar muito bem teoria e prática", trará resultados significativos. O momento de planejamento da aula promove uma dança dos "ses". 
O investimento no ensaio dos passos do tango ou do forró, dependendo do enfoque da aula, vale a pena. Conforme Demo (2012, p. 59), nos espaços de ensino

Aprende-se, principalmente, a aprender (habilidades), ou seja, habilidades de autoria e autonomia que servem para a vida toda, em especial para continuarmos sempre aprendendo, nos desconstruindo e reconstruindo. Não se trata de abandonar ou maltratar conteúdos, porque são indispensáveis. Mas não se pode deixar de investir na capacidade de estudar, argumentar, fundamentar, porque são elas que podem manter viva a pessoa pela vida afora em termos de aprendizagem incessante.

Ensinar é muito diferente de dar aula. Ensinar exige dedicação e comprometimento e por isso pressupõe a ação performática do profissional que sente prazer em tecer sua obra, profissional alquimista que pensa antes de selecionar os componentes das misturas. Dar aulas, por outro lado, por isso um mero ato de transmitir conteúdos, sem a preocupação do quanto a transmissão esteja se transformando em conexão de aprendizagens e da produção de significados.

Há também os momentos em que preparamos muito bem uma aula e que, por algum motivo, o resultado não condiz com aquilo que era esperado. No primeiro momento, nos frustramos um pouco, mas, em seguida, vem a reflexão: "Por que não deu tão certo? Onde e como eu poderia ter feito diferente". Estas reflexões pós aula são de extrema relevância. Mizukami (2002, p.51) coloca que "professor reflexivo é aquele capaz de analisar a própria prática e o contexto na qual ela ocorre, de avaliar diferentes situações de ensino/escolares, de tomar decisões e de ser responsável por elas."

Ensinar exige ter coragem de inovar e de ousar, por isso como professores somos privilegiados de estarmos no contínuo movimento do aprender, de vivermos a ideia do inacabamento sugerida por Paulo Freire. Arriscar usando uma estratégia de ensino diferente, arriscar entrando na aula de literatura declamando uma poesia; convidando um colega de outra área do conhecimento para assistir à nossa aula para que ele dê um parecer avaliativo: quanta aprendizagem! É reconhecer que "Ser capaz de arriscar é uma das coisas mais inteligentes para mudar" (CORTELLA, 2011, p. 29).

A escolha de estratégias não pode ser um mero desejo de fazer algo diferente e muito menos, o simples uso de dinâmicas ou técnicas que não contemplem o conteúdo que precisa ser dado e que não combinem com o conteúdo. Uma aula expositiva pode ser muito significativa se ela instigar a curiosidade fizer refletir, se promover o exercício do olhar especulativo, a formulação de hipóteses, se houver interação, se agregar significados, se fomentar o intercâmbio de ideias e levar à resolução de problemas.

Cabe a cada docente, reconhecer-se e assumir-se como profissional da educação comprometido com a sua missão de fazer a diferença nos espaços de ensino e aprendizagem tanto na educação básica quanto no ensino superior. Esta postura pressupõe a abertura para o diálogo, a pesquisa constante, a aproximação dos recursos tecnológicos para que neles o docente encontre um aliado para a criação, produção, solução de problemas e colaboração.

\subsection{PLANEJAR, SIM!}

A boa aula é como tudo na vida: tem início, meio e fim. Na vida, uma ou outra fase, às vezes, parece se estender mais e acabamos não gostando da situação ou querendo que não termine, mesmo que sabemos que precisamos passar por todas as fases. Assim também é com a aula, se ficarmos o tempo todo só na parte explicativa do assunto, correspondente à introdução, falando e explicando, sem fazermos uma pausa, para ouvirmos as contribuições dos estudantes ou senão abrirmos espaço para que o conhecimento explicado seja sintetizado em algumas frases ou se não exemplificarmos com situações 
conhecidas, trouxermos uma situação problema, um cálculo, um texto em que o exposto seja aplicado, uma notícia atual ligada ao tema, tudo será uma fase só e a monotonia tem grandes chances de se tornar uma ouvinte da aula. Por outro lado, se o fim chegar muito rápido, se não tivermos tempo para averiguar, comparar, esquematizar e classificar informações, também não gostamos. Tudo tem seu tempo, frase antiga e muito verdadeira também para a educação! Imbernón (2012) compara a aula a um romance ou a uma narrativa curta onde há uma contextualização, a introdução da trama e o desenlace final.

O olhar atento combinado com a dosagem de bom senso nos ajuda nestas situações: observar a reação dos estudantes, fazer a leitura do que os olhos dizem, do que o corpo atento ou irrequieto sinaliza.

A Educação 3.0 nos coloca no compromisso de revermos alguns conceitos. Participar da aula não significa responder uma ou outra pergunta de forma automática e repetitiva. Significa ouvir a pergunta do colega, contribuir acrescentando ou questionando algo, relacionar com outro tema, trazer exemplos do cotidiano para assim tecer uma rede de saberes. As perguntas nascem no terreno da curiosidade e da necessidade. Freire já afirmava "Como professor devo saber que sem a curiosidade que me move, que me inquieta, que me insere na busca, não aprendo nem ensino" (FREIRE, 2003, p. 65).

Qual é o espaço, em nossas aulas, destinado à participação dos estudantes na resolução de problemas, na elaboração de hipóteses e de teses? Se vier tudo pronto, se não houver espaço para as indagações e até para as mudanças de rumo no planejamento do professor em função de uma pergunta ou de uma relevante informação trazida por um colega, devemos nos perguntar sobre o real significado de participação e também do quanto está sendo apre(e)ndido. Aula bem planejada não vem engessada, os conteúdos podem ser vistos e trabalhados de diferentes perspectivas, por isso mudanças de rota não afetam a preservação dos conteúdos. A criatividade clama por espaço nas aulas do ensino superior e neste contexto

\footnotetext{
A Educação 3.0 assume que criatividade não é um traço inato da personalidade, mas algo que pode ser desenvolvido ao longo da vida. $\mathrm{O}$ aluno 3.0 valoriza a curiosidade e a criatividade - e deve ter espaço para exercitá-las em todas as áreas de conhecimento. Esse olhar atento para a criatividade tem razão de ser: os profissionais mais procurados no século XXI são aqueles que conseguem encontrar soluções alternativas em cenários adversos, com poucos recursos ou em ambientes hostis. Eles se sentem compelidos pelo que ainda desconhecem, não têm medo de inovar e estão em constante atualização (SASSAKI, 2015, p. 27).
}

E no final da aula a pergunta deveria ecoar assim: O que meus alunos aprenderam hoje? Cabe aqui destacar que, os anos de aprendizagem com o Projeto (In) sana possibilitam ao docente, a cada aula da disciplina de literatura infantil, depois do texto da autora do dia ser compartilhado, uma análise do quanto o conteúdo da aula anterior foi apre(e)endido.

A autoavaliação docente em relação ao que os alunos aprenderam ou não, de forma alguma, pressupõe-se que a aprendizagem depende somente do professor. $\mathrm{O}$ aluno também precisa querer aprender e fazer a sua parte. Podemos, todavia, instigá-lo e provocar o apetite pelo conhecimento

Cada vez que conseguirmos promover a interação do grupo e a construção coletiva de conhecimentos, momentos em que os sujeitos são ensinados a ouvir os colegas, a dialogar, a questionar e a pensar sobre contribuição do outro, concordando ou discordando e argumentando, estaremos contribuindo para a formação de um profissional mais humano que, provavelmente, no futuro quando estiver atuando, será capaz de se colocar no lugar do outro para propor projetos, trabalhos coletivos e consequentes transformações na sociedade. 
Não há mais um único objetivo imutável a ser atingido: a partir de agora, a aprendizagem ocorre a partir da solução de problemas reais; cada aluno ou grupo de alunos enveredando por um caminho alternativo e adquirindo, enquanto isso, seu conjunto particular de conhecimentos, habilidades e competências (SASSAKI, 2015, p. 7).

Bringhouse e Woods (2010) nos alertam sobre o compromisso que as escolas deste novo milênio terão com a utilização e o fomento da inteligência compartilhada na produção de conhecimentos. Juntos professores e estudantes reestruturarão conhecimentos e aplicá-los-ão em novos contextos.

Incentivar a pesquisa é outro elemento fundamental no planejamento das aulas. A pesquisa pode acontecer durante ou fora da aula. Só não dá para pressupor que todos os estudantes saibam que do processo de pesquisar alguns elementos são fundamentais como: ler, identificar ideias-chave, separar conceitos principais dos secundários, sistematizar, sintetizar, associar e interligar conceitos, comparar fontes e registrar. Mesmo sendo estudantes do superior, cabe ao professor dar dicas de como se pesquisa, mencionar que elementos são imprescindíveis no registro da pesquisa, explicar o que significa registrar, indicar referenciais etc. A investigação metodológica (estudo de caso) que embasa o presente artigo, pressupõe na sua realização, uma pesquisa constante por parte das autoras. Escrever um texto coletivo, cuja temática é a insanidade humana, exige das estudantes de pedagogia uma pesquisa a respeito do tema: como caracterizar a protagonista que sofre com sintomas de esquizofrenia? Como ela age? ou então: que cuidados precisamos ter quando produzimos um texto narrativo?

Retomando as etapas de uma aula, gostaria de chamar a atenção para um outro aspecto no momento do desenvolvimento (meio) da aula: o debate de textos lidos. A indicação da leitura de livros e textos é uma ação bastante conhecida e relevante no ensino superior. Assim, algumas perguntas tornam-se fundamentais para nossa reflexão: Quando debatemos o texto, partimos do princípio de que todos o leram? O que significa leram? Compreenderam? E durante o debate: todos participam? Como envolvemos os tímidos, aqueles que demoram um pouco mais para se posicionarem? Se meu jeito de debater é lançando apenas perguntas ou destacando algumas partes, como atingirei os estudantes que não costumam fazer a leitura ou ainda aqueles que descobriram um truque que, alguns deles consideram eficiente: "Leio um pouco nas primeiras duas páginas, algo no meio do polígrafo e ainda no final. Sublinho e o professor acredita que li tudo." Claro, aqui, como professores poderíamos dizer: "Azar o dele. A quem este estudante pensa que está enganando? Só a si mesmo." É verdade, o estudante do ensino superior deveria ter consciência de que esta postura lhe prejudica. Mas, será que ele tem esta consciência? Lembremo-nos das vezes que nós retornamos à sala de aula como estudantes, participando de momentos de formação continuada, quando sentamos na cadeira de aluno, sempre fazemos o que nos é solicitado?

Na Educação 3.0, o professor deixa de ser o sol, o centro da sala de aula, para orbitar em torno de seus alunos. Sem a obrigação de ser fonte exclusiva de conhecimento, ele adquire maiores responsabilidades: a de compreender seus alunos, orientá-los individual e coletivamente, coordenar projetos e atividades, introduzir novas ferramentas (ou ferramentas conhecidas, mas com novos propósitos) e provocar reflexões (SASSAKI, 2015, p. 18).

O processo de comunicação, conforme Imbernón (2012, p.64) é o conceito-chave do ensino. A comunicação começa desde o momento em que o professor entra na sala: é o seu jeito de cumprimentar, de dar feedback sobre um trabalho realizado, de resgatar o fio da reflexão do dia anterior, de dar continuidade à aula. Comunicação significa cuidar do que dissemos e como o fazemos, é valorizar as contribuições do estudante, é olhar para a sociedade e trazer contribuições para intervir nela, enfim, é a uma ação em união com o outro. É ter cuidado com as informações que trazemos para que estas 
realmente contribuam para uma aprendizagem significativa, é perceber o tempo dos alunos. É o momento de estar com o outro que quer aprender e, sobretudo, devemos estar conscientes de que também nós educadores temos muito a aprender com as intervenções dos nossos alunos. Suas perguntas nos ensinam, o jeito de encararem o mundo e de lidarem com a tecnologia é uma constante aprendizagem.

Já refletimos sobre duas fases da aula o começo e o desenvolvimento, mas e o fechamento, qual á a sua importância? Há um fio invisível que liga os diferentes momentos de ensino. Os conhecimentos estão interligados e por isso devemos ter o cuidado de mostrar esta relação entre os temas, ligar assuntos, enfatizar a necessidade de olharmos para a transversalidade dos temas e de assim os compreendermos. O final da aula pode ser um início perfeito para a aula seguinte, a pesquisa solicitada trará elementos para uma discussão inicial (In) sana serve de exemplo para o que está sendo sugerido: continuidade entre os conteúdos, retomada de aspectos e projeção futura.

\title{
3 CRIATIVIDADE E REGISTRO: IMPULSO À AUTORIA DOCENTE NAS AULAS DE LITERATURA
}

As palavras conectadas entre si, ligadas pelos pensamentos conjuntos, nos ensinam que mudar não é tão difícil quando caminharmos com os outros, confabulando, tecendo redes de saberes e amparados nas teias de relações! A metodologia focada na participação ativa dos estudantes, incentivando a autonomia e a criatividade, levará às transformações na sociedade. Pelo protagonismo, crianças, jovens e adultos descobrirão que a vida só vale a pena ser vivida se for com solidariedade e amor e a literatura pode ser a mestra que aponta os caminhos.

\begin{abstract}
A literatura, assim como as outras artes, dá forma concreta a sentimentos, dilemas, angústias e sonhos, por meio de representações simbólicas, criadas pela imaginação. Consequentemente, embora seja fictício, o texto literário estabelece correspondências com a realidade factual e a produção artística, retomando o passado, antecipando o futuro, explorando a herança literária para transformá-la pela ação criadora, visto que as representações poéticas trazem fragmentos da realidade, além de dialogarem com a tradição estética (SARAIVA, 2006, p.29).
\end{abstract}

No projeto de estímulo de criação e autoria, analisado no presente artigo, o início de cada encontro semanal é marcado pela ansiedade do estudante autor que espera o momento de mostrar na tela o novo capítulo da história coletiva. A leitura é realizada pela autora, seguida pelos seus comentários e das contribuições das colegas. Conforme afirma Koch e Elias (2016, p. 85)

\begin{abstract}
Na leitura de um texto, acompanhamos o raciocínio do autor, identificamos os seus argumentos, ativamos vários conhecimentos, preenchemos as lacunas, e construímos um sentido. E tudo isso acontece porque o autor, pensando no objetivo e no leitor de seu texto, elege um tema ou assunto e o desenvolve, observando um equilíbrio variável entre duas exigências fundamentais: repetição (retroação) e progressão.
\end{abstract}

O registro é um recurso facilitador da construção coletiva de ideias e cria uma unidade na diversidade do grupo. Pela escrita os estudantes revelam-se e narram-se.

Dialogar, saber escutar as palavras, silenciar para contemplá-las e ouvir o que elas têm a dizer é um compromisso docente. Zambrano (apud LARROSA, 2004, p. 35) adverte sobre o valor da palavra escrita: "Escrever é primeiro um impor silêncio: calar as palavras da comunicação mais banal, a que responde às necessidades da vida mais banais, para buscar, em uma solidão silenciosa, o que não se pode dizer: ...mas isso que não se pode dizer, é o que se tem que escrever." 
O convite, a partir das palavras de Zambrano é para a percepção das palavras escritas e que se tente chegar mais perto delas. Larrosa (2004, p.15), no texto Dar a ler... talvez, provoca o leitor para se aproximar mais das palavras, senti-las e permitir que elas se comuniquem. Com Dar a ler... talvez, o autor instiga-nos para um olhar diferente para o texto: ler um texto como se nosso contato com ele fosse pela primeira vez. Não ler, considerando-se já, de antemão, conhecedor do texto. Simplesmente deixar se encantar por ele. O autor sugere que para "dar a ler é preciso esse gesto às vezes violento de problematizar o evidente, de converter em desconhecido o demasiado conhecido, de devolver certa obscuridade ao que parece claro, de abrir uma certa ilegibilidade no que é demasiado legível" (LARROSA, 2014, p.16).

A escrita da história coletiva promove momentos de silêncio, de apreciação, de diálogo e de intervenções das colegas, avaliadas pelas estudantes como momentos de crescimento pessoal e profissional. O desafio consiste em aceitar os questionamentos das colegas diante de algum aspecto da narração. Saber ouvir para reagir com serenidade.

As pessoas, tecendo redes de palavras, formando teias de significados, nos ensinam que é preciso deixar espaço para o estranhamento. Um olhar de admiração e surpresa sobre algo já conhecido pode fazer com que o misterioso, o antes não percebido, se mostre diante dos novos olhos, que desejam ver, mesmo que os olhos, no primeiro momento, fiquem embaçados ou até ofuscados. Todavia, é preciso parar para refletir para perceber o que sucede ao nosso redor.

Como sugere Alarcão (2004, p.32), “O desenvolvimento do espírito crítico faz-se no diálogo, no confronto de ideias e de práticas, na capacidade de se ouvir a si próprio e de se autocriticar." E nesse processo a escrita desempenha um papel fundamental.

A escrita é um espaço de silêncio para lembrar a mudança e vislumbrar os rastros deixados, mas, ao mesmo tempo, nos leva a projetar novos espaços imaginários à luz daquilo que já foi, do que é e do futuro que ainda é incerto porque não é. É também um espaço para a descoberta de cada rosto, de cada olhar, das diferentes maneiras de pensar, de sentir e de viver a realidade (CARRILO apud ZABALZA, 2004, p.29).

No momento em que a escrita fizer parte da vida das estudantes e docentes, abre-se também um atalho para a efetivação do processo de ação-reflexão-ação, que Paulo Freire já propunha.

$\mathrm{O}$ ato de registrar, conforme afirma Warschauer (2001), como um artesanato intelectual feito ao longo do processo, ajuda a construir a memória compreensiva, que é diferente daquela repetitiva e mecânica. O registro possibilita a retomada de reflexões realizadas no passado. Permite ao leitor a análise da evolução dos pensamentos, ou, o que também pode ocorrer, a percepção da estagnação, mas sempre dará a possibilidade de ser um ponto de partida. Os pensamentos e as palavras, quando integrantes de uma teia de saberes, possibilitam o reajuste e a recolocação de fios e o desfiar de outros para o tecer de novos pontos. De acordo com a autora:

Este "ter presente" o já acontecido é de especial importância na transformação do agir, pois oferece o conhecimento de situações arquivadas na memória, capacitando o sujeito a uma resposta mais profunda, mais integradora e mais amadurecida, porque menos ingênua e mais experiente, de quem já aprendeu com a experiência. Refletir sobre o passado (e sobre o presente) é avaliar as próprias ações, o que auxilia na construção do novo. E o novo é a indicação do futuro. É o planejamento (WARSCHAUER, 2001, p.63).

Os estudantes, futuros professores, que hoje compartilham dos espaços nos ambientes do ensino superior, desde o berço (mesmo que não compreendessem o significado), já vivenciaram notícias acerca da desvalorização do magistério, das dificuldades enfrentadas pelos docentes, o baixo salário e outros 
itens que complementam a lista de dificuldades vividas pelo magistério. Aliás, a cada ano, a relação de desafios apresenta um considerável crescimento, o que pelos mais pessimistas é visto como o fundo do poço e para outros, os abrigadores dos sonhos, a oportunidade de transformar as pedras do fundo do poço em degraus para uma educação de qualidade e que produza significados.

Diante deste cenário, torna-se imprescindível olhar para os sujeitos, que cientes de todas estas dificuldades, optam pelo magistério e que merecem a valorização e apoio da sociedade.

A combinação do registro reflexivo com o diálogo acerca do que foi escrito promove o crescimento do sujeito que deixa de ser um mero executor de tarefas para assumir o papel de protagonista pensante que, por ser conquistado, pelas histórias vividas na escola, torna-se, cada vez mais engajado no seu enredo e zela pela atuação de todos os atores.

\section{CONSIDERAÇÕES FINAIS}

Tudo isso nos leva a dizer conscientemente: lecionar é muito bom. Se como professores tivermos um olhar atento e cuidadoso para a aprendizagem dos nossos alunos, se vivermos mais a empatia, quando estivermos em sala de aula, não nos faltarão inspirações.

A metodologia adotada com as estudantes de Pedagogia, na disciplina de Literatura Infantil, para o registro e a produção coletiva na página do Facebook (In) Sana nos mostra que, a conquista para a aprendizagem, não depende de poções mágicas e nem de feitos heroicos. Não há segredos. Nem o tempo muda a necessidade básica das pessoas no processo da produção de conhecimentos: olhar nos olhos, despertar a curiosidade, buscar resoluções para problemas do cotidiano. Como nos contos de fada, quando João e Maria se dão conta que não adianta jogar migalhas de pão para marcar o caminho andado, estudantes engajam-se quando notam que a aprendizagem faz sentido e que acrescenta algo em suas vidas.

O registro semanal realizado pelas estudantes é recheado de criatividade e com uma reflexão significativa, porque escrever bem, recuperando as reflexões da aula anterior, tornou-se um desafio para cada autora. Surgiu uma competitividade positiva entre as autoras. A pesquisa tornou-se uma prática constante que surgiu da curiosidade e da necessidade delas quererem saber mais sobre os temas e de como esses estavam interligados.

Buscar rotas alternativas para compreender os diferentes sujeitos e os cenários nos quais atuam deve ser um compromisso dos educadores. Comprometer-se com a aprendizagem de crianças e jovens fará com que o tempo solidifique palavras que não podem sumir do dicionário vital da escola: amor, solidariedade e respeito!

O constante processo reflexivo leva à compreensão de que as mudanças são lentas, que é necessário tempo, que primeiramente, deve ocorrer um processo interno de conscientização da necessidade da mudança por parte de cada educador e educadora.

Fica assim, como compromisso da academia, oferecer muitas oportunidades para que nossos jovens professores, conscientes da sua responsabilidade com a educação, sentindo-se comprometidos e vinculados com os alunos, façam a diferença nas escolas em que atuam, buscando a inovação, atentando à aprendizagem significativa, encorajando a autonomia dos alunos, estimulando a criatividade e a solidariedade e, sobretudo, agindo com amor e sensibilidade.

\section{REFERÊNCIAS}

ALARCÃO, Isabel. Professores reflexivos em uma escola reflexiva. São Paulo: Cortez, 2004. 
ALVES, Rubem. Educação dos sentidos. Campinas, SP: Verus, 2005.

BARTHES, R. Aula. São Paulo: Cultrix, 1977.

BRIGHOUSE, Tim; WOODS, David. Como fazer uma boa escola? Porto Alegre: Artmed, 2010.

CORTELLA, Mário Sérgio. Qual é a tua obra? Inquietações propositivas sobre gestão, liderança e ética. 13. ed. Petrópolis: Vozes, 2011.

DEMO, Pedro. O mais importante da educação importante. São Paulo: Atlas, 2012.

FREIRE, Paulo. Pedagogia da autonomia: saberes necessários à prática educativa. 27. ed. São Paulo: Paz e Terra, 2003.

IMBERNÓN, Francisco. Formação continuada de professores. Porto Alegre: Artmed, 2012.

LARROSA, Jorge. Linguagem e educação depois de Babel. Belo Horizonte: Autêntica, 2004.

MIZUKAMI, Maria da Graça Nicoletti et al. Escola e aprendizagem da docência: processos de investigação e formação. São Carlos: EdUFCAR, 2002.

SASSAKI, Claudio. Educação 3.0: uma proposta pedagógica para a educação. São Paulo: Geekie, 2015. Disponível em: <http://materiais.geekie.com.br/educacao-proposta-pedagogica〉. Acesso em: 21 jun. 2017.

SARAIVA, Juracy Assmann; MÜGGE, Ernani. Literatura na escola: propostas para o ensino fundamental. Porto Alegre, RS: Artmed, 2006.

WARSCHAUER, Cecília. A roda e o registro: oportunidades formativas na escola e fora dela. Rio de Janeiro: Paz e Terra, 2001.

ZABALZA, Miguel A. Diários de aula: um instrumento de pesquisa e desenvolvimento profissional. Porto Alegre: Artmed, 2004. 